\title{
Auditing community screening for undescended testes
}

\author{
R C Tamhne, S N Jarvis, A J R Waterston
}

\begin{abstract}
Different ways of auditing screening for undescended testes, using Hospital Activity Analysis data, hospital case notes, and community/general practice records are described. The cumulative orchidopexy rate per 1000 male births in successive birth cohorts is a simple tool for monitoring trends within a health district. Information gained from community/general practice records is valuable in highlighting problem areas in screening, such as the lack of clear diagnostic criteria and referral pathways.
\end{abstract}

Screening for undescended testes is an important part of child health surveillance. Newcastle Health Authority policy in recent years has been to screen boys for undescended testes at birth, at age 6 weeks and 1 year, and at school entry. The report of the Joint Working Party on child health surveillance has recommended screening for undescended testes at birth, at age 6 weeks and 8 months, and once more in preschool years: ${ }^{1}$ The report highlights the need for regular audit/evaluation of all screening programmes. Further general emphasis on clinical audit has also come from the recent United Kingdom government white paper. ${ }^{2}$

Several methods of auditing screening for undescended testes have been described. ${ }^{3-5}$ There remains a need for each health district to have an ongoing audit of screening for undescended testes that is simple and based on routinely available data. The present study was aimed at evolving such a method.

\section{Methods}

A printout of Hospital Activity Analysis data (now Körner inpatient data) on all patients resident within the boundaries of Newcastle Health Authority and who had an orchidopexy between 1974 and 1986 was obtained from the Northern Regional Health Authority. Casenotes of children born between 1980 and 1985 (inclusive) were studied. Community health and general practice records of the children were examined where necessary. From this data, a screening profile before diagnosis of undescended testes was constructed for each child who underwent orchidopexy and the original source of diagnosis was classified as neonatal screening, community screening or other, the latter accounting for those diagnosed after parent initiated consultations or opportunistic detection.

\section{Results}

A total of 1000 operations for orchidopexy were conducted on Newcastle residents between 1974 and 1985. Figure 1 shows the average age at operation (for boys under 16 years) for each year between 1974 and 1985, together with the annual proportion of all operations conducted by age 2 and by age 5 . Although average age of orchidopexy has only fallen by about one year, the proportion of 'early' operations rose appreciably from 1981 .

Altogether 311 children born between 1974 and 1985 had their first orchidopexy by the end of 1986. The following analyses relate to the years of birth of these children rather than the year of operation.

Figure 2 shows the average age at operation for these successive birth cohorts between 1974 and 1985. The analysis is repeated as if it were being done every second year between 1980 and 1986. It can be seen that the average age at

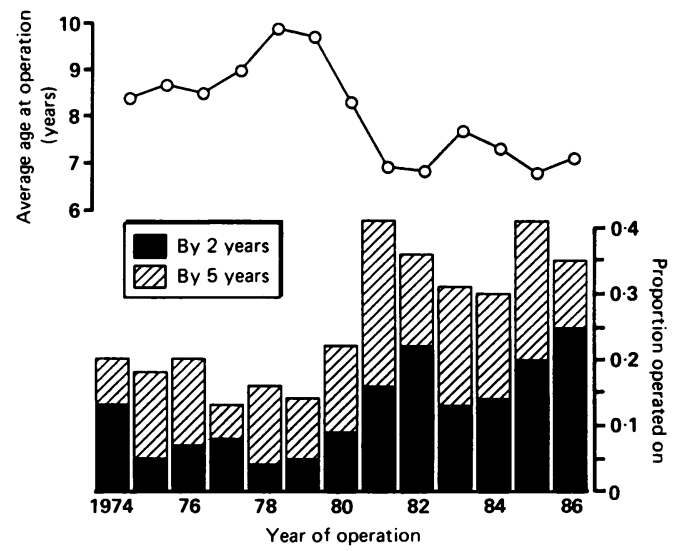

Figure 1 Average age at orchidopexy and proportions of 'early' operations in 1974-86.

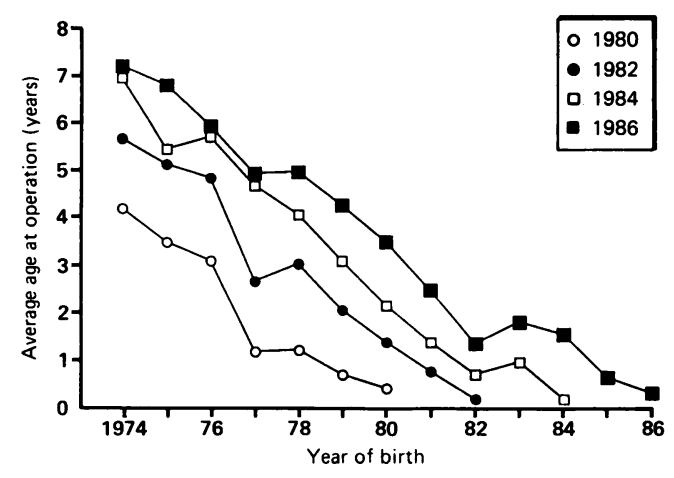

Figure 2 Average age at orchidopexy for successive birth cohorts 1974-86. 

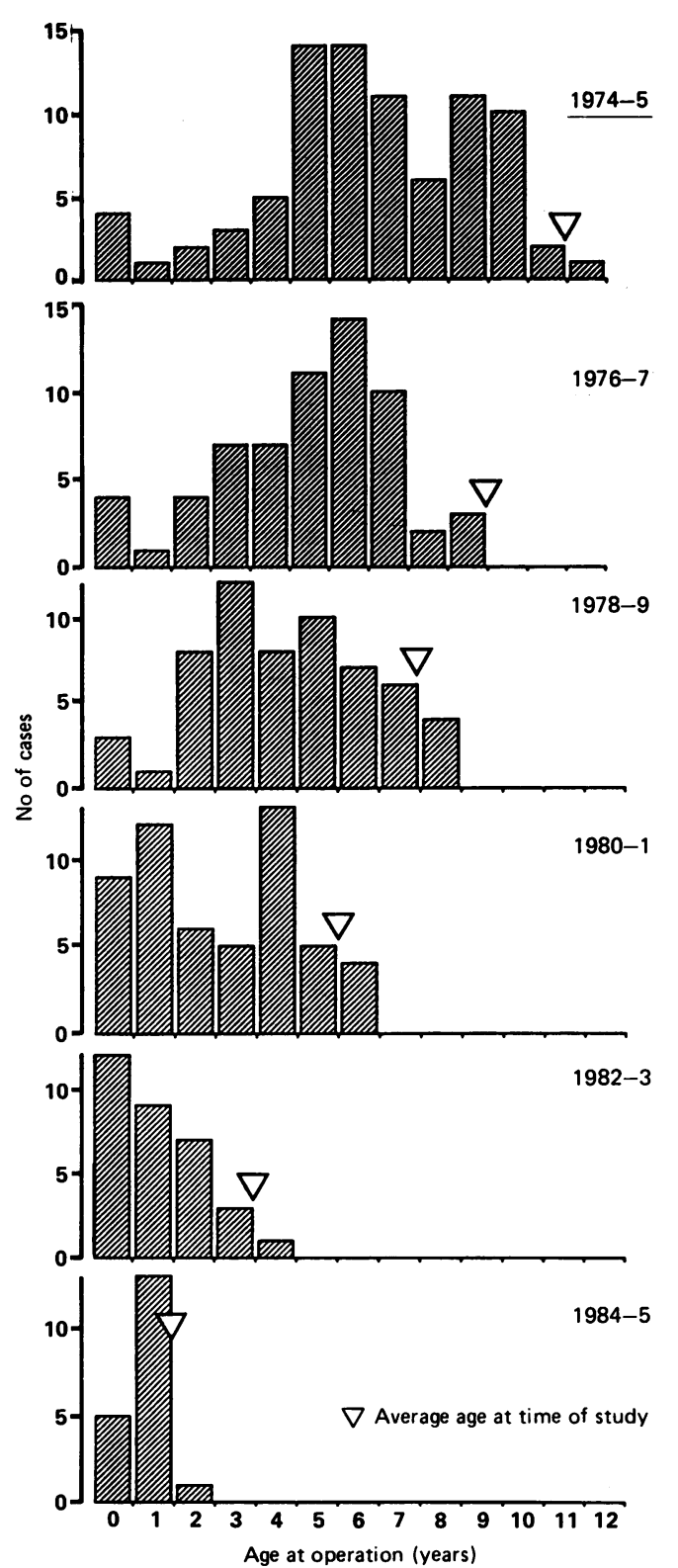

Figure 3 Distribution of age at orchidopexy in birth cohorts of two years (1974-85).

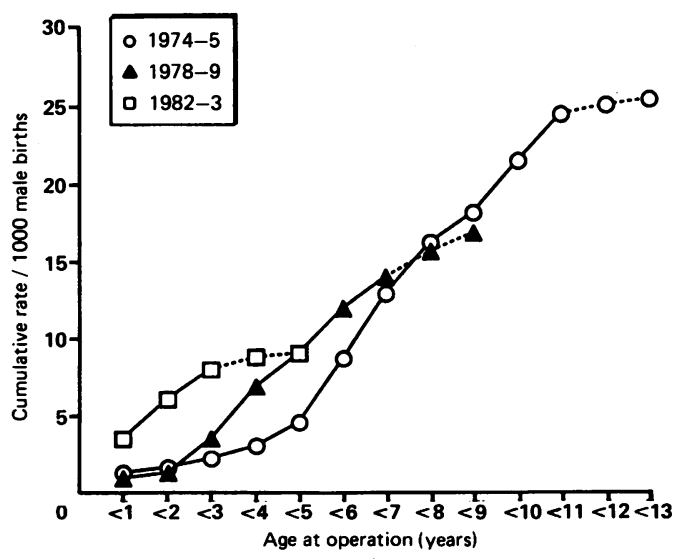

Figure 4 Cumulative rates of orchidopexy by age for three birth cohorts. The dotted sections for each cohort graph are incomplete as some children had not reached this age at the time of analysis. operation for any particular birth cohort does not stabilise until the children are at least 7 years of age.

Figure 3 shows the distribution of the age at operation for biannual birth cohorts between 1974 and 1985. The progressive shift towards earlier operations is now more clearly seen even though the right hand end of the distributions are probably incomplete.

Figure 4 shows the cumulative rate of first orchidopexy per 1000 male births for three of the same cohorts. This last method of demonstrating the orchidopexy experience for successive cohorts of children clearly shows the more rapid accumulation of cases in recent years. Indeed between 1974 and 1983 there has been a highly significant upward trend in the rate of operations by the age of 2 years in successive cohorts $\left(\chi^{2}\right.$ for trend $=19 \cdot 7, \mathrm{df}=1$ ).

Hospital case notes of the 105 children born between 1980 and 1985 were requested and 82 were actually seen. For those cases that were not detected neonatally the community records (42 children) and general practice records (47 children) were seen.

The interval between age at referral and age at first orchidopexy varied little (average delay $1980 / 1$ cohorts $=11 \cdot 5,1982 / 3=8 \cdot 5$, and $1984 /$ $5=9.6$ months). This suggests that at least for recent years of birth any changes in age at orchidopexy are related to changes in age at referral rather than surgical policy.

Figure 5 shows the proportion of cases detected by neonatal and community screening or by other means in the cohorts born between 1980 and 1985. Community screening appears to make an important contribution to the pick up of late diagnosed cases but also more recently to those referred as infants.

The table gives the outcome at two screening events in the community, namely at age 6 weeks and 1 year, for children who were still undiagnosed by those ages and who eventually had an orchidopexy. Instances where undescended testes was detected, but no definitive action (that is, referral to the surgeons) was taken as a result were also recorded.

\section{Discussion}

Average age at operation (fig 1) for successive years of operation shows a steady decline in recent years, from 8.5 years in 1974 to $7 \cdot 2$ years in 1985 . This compares with the average age of operation of 9 years in 1974 and $7 \cdot 7$ years in 1982 described by Boggis and Rowlatt. ${ }^{3}$ Average age at operation in any given year is liable to be seriously distorted by a few cases operated on at older ages, however, and does not necessarily reflect the effects of recent trends in surveillance for undescended testes. Its value can be somewhat enhanced by noting the proportion of children operated on by a certain age. In our case for instance, the proportion operated on by the age of 5 years has increased from $20 \%$ in 1974 to $35 \%$ in 1986 . In the series of Bishop and Whittaker, only $9 \%$ were operated on by the age of $5 .{ }^{6}$ However, the limitation imposed by orchidopexies done in older children still stands.

The average age at orchidopexy for successive birth cohorts (fig 2) shows a downward trend for recent cohorts. This gives a.fallacious impression, 


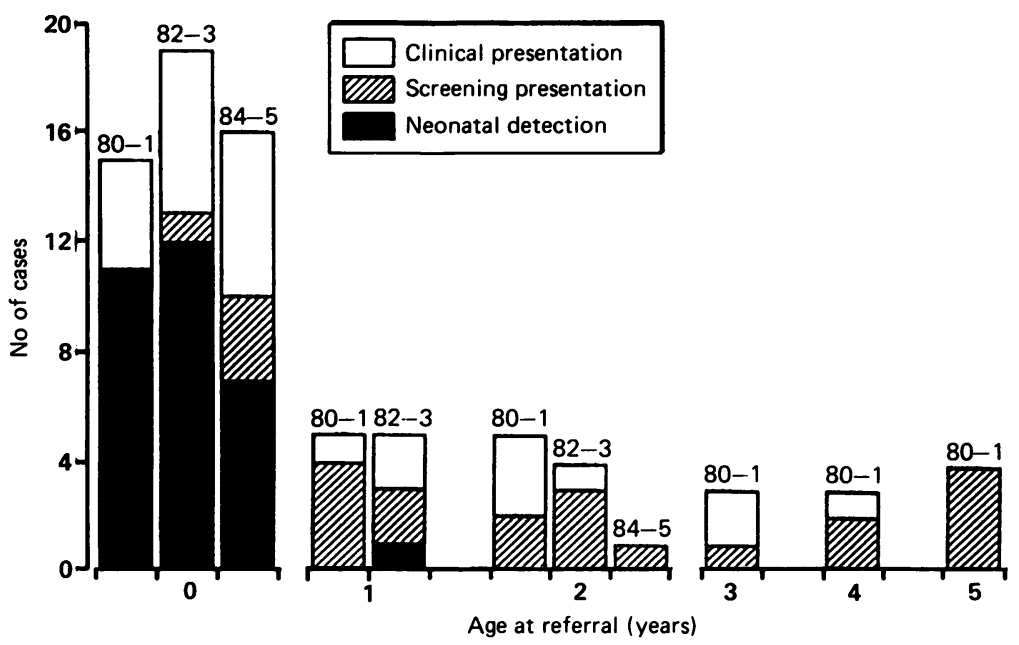

Figure 5 Age at referral for orchidopexy by source in birth cohorts of two years. the left of the recent cohort graphs in fig 4 does therefore seem to represent a genuine trend towards earlier orchidopexies.

As the interval between referral and operation has remained virtually constant between 1980 and 1984 , it seems that the explanation for these changes in orchidopexy rates might be found by examining the routes of referral. Our search of casenotes shows that although neonatal detection accounts for up to a third of cases, it has not made an increased contribution recently. On the contrary fig 5 suggests an increase in cases detected by community screening in recent birth cohorts. The most interesting point about the data on community screening at 6 weeks and 1 year, however, is the proportion of cases where undescended testes was detected, but where no referral to surgeons was made. There is a need to set clear guidelines for the diagnosis of undescended testes and for referral pathways.

Outcome of checks for undescended testes at age 6 weeks and 1 year

\begin{tabular}{|c|c|c|c|c|c|c|}
\hline \multirow[t]{2}{*}{ Cohort } & \multicolumn{3}{|l|}{ Age 6 weeks } & \multicolumn{3}{|l|}{ Age 1 year } \\
\hline & $\begin{array}{l}\text { No of } \\
\text { records seen* }\end{array}$ & $\begin{array}{l}\text { No who had } \\
\text { check done }\end{array}$ & $\begin{array}{l}\text { No detected } \\
\text { (No who had } \\
\text { no action taken) }\end{array}$ & $\begin{array}{l}\text { No of } \\
\text { records seen }\end{array}$ & $\begin{array}{l}\text { No who had } \\
\text { check done }\end{array}$ & $\begin{array}{l}\text { No detected } \\
\text { (No who had } \\
\text { action taken) }\end{array}$ \\
\hline $\begin{array}{l}1980 \\
1981 \\
1982 \\
1983 \\
1984 \\
1985\end{array}$ & $\begin{array}{r}13 \\
10 \\
5 \\
4 \\
4 \\
3\end{array}$ & $\begin{array}{l}8 \\
8 \\
4 \\
2 \\
4 \\
3\end{array}$ & $\begin{array}{ll}2 & (2) \\
2 & (2) \\
2 & (1) \\
1 & (1) \\
4 & (3) \\
2 & (1)\end{array}$ & $\begin{array}{r}13 \\
10 \\
3 \\
4 \\
1\end{array}$ & $\begin{array}{l}8 \\
4 \\
3 \\
4 \\
1\end{array}$ & $\begin{array}{ll}3 & (1) \\
3 & (1) \\
2 & (2) \\
3 & (1) \\
1 & (1)\end{array}$ \\
\hline
\end{tabular}

${ }^{*}$ Records were traced for $90 \%$ of children eligible for screening.

however, because some of the children in the younger cohorts would not yet have their undescended testes detected and operated on. When they do get operated on, the average age of operation will move upwards. Furthermore these 'late operation' cases have an increasingly disproportionate effect on the average age for their cohort. The indications are that such a method of analysis will not give a stable picture until several years after the screening events of interest.

Distribution of age at operation (fig 3) for successive birth cohorts appears to show an increasing proportion of cases being operated on in younger age groups in recent years. This picture is somewhat complicated by the fact that each cohort's experience is incomplete.

Of the analyses based on Hospital Activity Analysis data alone, the cumulative rate of orchidopexy per 1000 male births (fig 4) comes closest to being a good outcome indicator. The main reservation with this method of analysis is whether there is variation in the underlying frequency of undescended testes or of other factors which might contribute to cumulative incidence (for example, operations on retractile testes). This point was addressed by Chilvers et al who estimated that there had been a doubling of cumulative incidence of orchidopexy to $2.9 \%$ by age 15 years between the 1952 and 1977 national birth cohorts. ${ }^{7}$ The most complete cumulative rate in our series is that for the 1974 cohort at $2 \cdot 6 \%$ and our findings therefore support their extrapolated estimate. This possible trend does not seem likely to explain the almost fourfold increase in rates of orchidopexy under 3 years of age, however, which we have observed between the 1974 and 1983 cohorts. Furthermore we believe that as virtually all these operations were carried out by a stable team of three paediatric surgeons there is unlikely to be a problem of inappropriate operations. This shift to
We appreciate that the approach to audit of screening described above does not meet the need for comprehensive evaluation of a screening programme. We cannot describe the coverage for screening nor the false positive rates. Such an audit, however, which uses only routinely available data, is valuable for monitoring trends within a district and for regional or national comparisons. For this purpose birth cohort specific cumulative orchidopexy rates by age 2 are an effective contemporary tool. Such an audit may be supplemented by study of the hospital casenotes and community/ general practice records, at five to 10 year intervals, to pinpoint the problem areas in the screening or referral processes.

These latter investigations would be simplified if it were routine practice for a copy of any discharge letter after orchidopexy to be sent to the community unit for linkage to that child's original preschool screening record.

We are most grateful for the help of Newcastle consultant paediatric surgeons and general practitioners in allowing access to their casenotes. This work was undertaken while Dr Tamhne was on secondment from the Community Unit, Newcastle Health Authority.

1 Hall DMB, ed. Health for all children. (Report of the Joint Working Party on Child Health Surveillance.) Oxford: Oxford University Press, 1989.

2 Secretaries of State for Health, Wales, Northern Ireland and Scotland. Working for patients. London: HMSO, 1989. (Cmnd 555.)

3 Boggis ARJ, Rowlatt RJ. A study of sources of delay in diagnosis and treatment of undescended testicle. $\mathcal{J} R$ Coll Gen Pract 1984;34:440-6.

4 Reece Smith H, Moisey CU. The undescended testicle: a continuing failure. $\mathrm{Br} \mathrm{Med} \mathcal{f}$ 1984;288:1653.

5 Cooper BJ, Little TM. Orchidopexy: theory and practice. BrMed f 1985;291:705-7.

6 Bishop MC, Whittaker RH. Cryptorchidism: a renewed plea. Br Med F 1979;278:407-8.

7 Chilvers C, Pike MC, Forman D, et al. Apparent doubling in 1962-81. Lancet $1984 ; \mathrm{ii}: 330-2$. 